Atrkivoc

Free to Authors and Readers
A Platinum Open Access Journal for Organic Chemistry

Paper

DOAJ Seal

Arkivoc 2021, part vi, $45-58$

\title{
On the natural selection of high performance polymers
}

\author{
Ian Hamerton* and Robert J. Iredale
}

The Bristol Composites Institute, Department of Aerospace Engineering, School of Civil, Aerospace, and Mechanical Engineering, Queen's Building, University Walk, University of Bristol, Bristol, BS8 1TR, U.K. Email: ian.hamerton@bristol.ac.uk

Received 03-20-2021

Accepted Manuscript 05-06-2021

Published on line $05-12-2021$

\section{Abstract}

The high performance polymer market can be a fickle one for manufacturers, subservient to the whims of the end user. The materials often serve narrow, exotic markets and are thus produced in significantly smaller quantities than their higher tonnage, commodity cousins. Often, these more expensive, thoroughbred materials tend to be acquired and divested more readily than more humble products that constitute the core business. For example, a cursory glance at the development of cyanate ester monomers, first reported in the 1960s by Bayer AG, shows that the business changed hands on no fewer than seven occasions during the intervening forty years. In this reflective essay, the development of a carefully selected group of high performance polymers is contrasted in order to identify the key elements that contribute to the success (or failure) of a product.

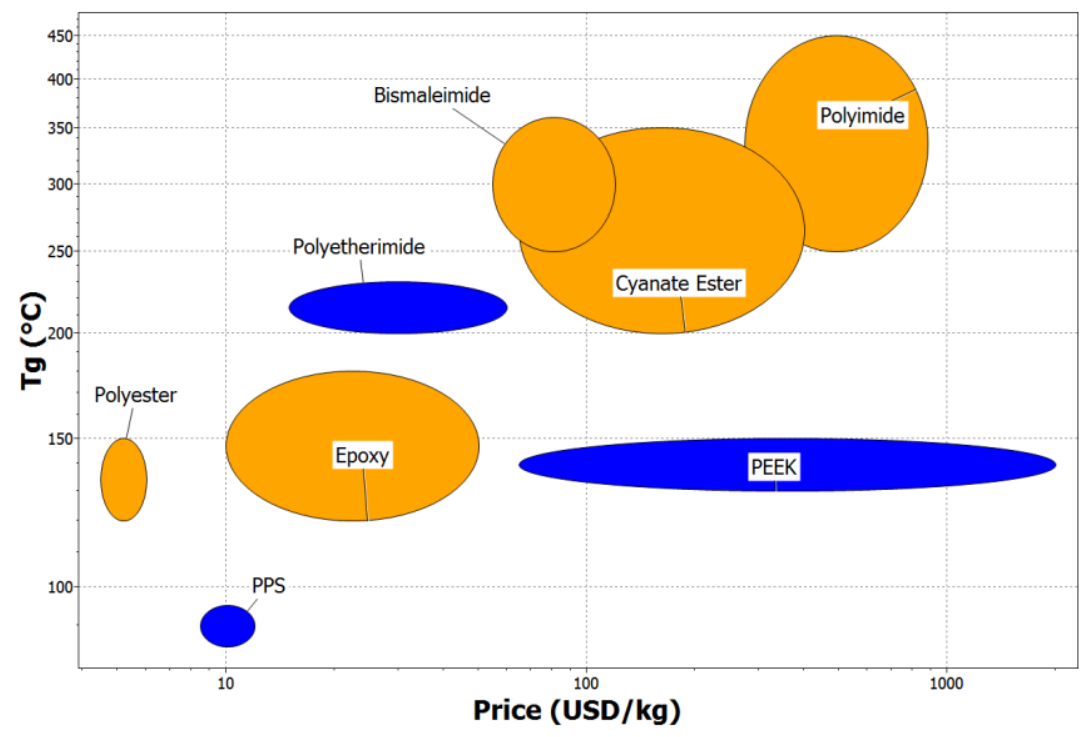

Keywords: High performance polymers; composites; market forces; evolution 


\section{Introduction}

"I think it inevitably follows, that as new species in the course of time are formed through natural selection, others will become rarer and rarer, and finally extinct. The forms which stand in closest competition with those undergoing modification and improvement will naturally suffer most." So, wrote Charles Darwin ${ }^{1}$ in his ground breaking and controversial publication outlining the theory of natural selection in 1859. Whilst the evolution and growth (or decay) of commercial polymers obey quite different pressures (in many cases a most 'unnatural' selection), it is highly informative to look more closely at the manner of the evolution of selected high performance polymers; some widely used, others occupying a small niche to inform the development of future high performance polymers.

The very definition of a 'high performance' polymer is an invidious one and arguably differs depending on the use to which the polymer is put, although some basic attributes (e.g. high glass transition temperature, $\mathrm{T}_{\mathrm{g}}$, high tensile strength, and thermal stability, etc.) commonly arise in this connection ${ }^{2}$. A comparison of selected properties of high performance polymers (both thermosets and thermoplastics) is shown in Figure 1, along with a guideline price. The latter is also sometimes hard to identify since discounting is occasionally used to introduce a material into an established market (and this is particularly true of PBZ, as the price range does not properly reflect the potential price once the business stabilizes), but many personal communications were held to substantiate published prices.

For the purposes of the present discussion, the commercial polymer families are all thermosetting polymers, subject to similar processing issues or selection criteria. Consequently, a series of established high performance commercial thermoset polymers (epoxy resins ${ }^{3}$, ER; bismaleimides ${ }^{4}, \mathrm{BMI}$; and cyanate esters ${ }^{5}$, $\mathrm{CE}$, Figure 2) were selected together with the forerunner of all synthetic polymers, phenol-formaldehyde resins $^{6}(\mathrm{PF})$ from 1907, a comparatively exotic family, benzocyclobutenes ${ }^{7}, \mathrm{BCBs}$; and the most recent addition to the commercial thermoset family, polybenzoxazines ${ }^{8}$ (PBZ). Selected representative properties are given for these materials (Table 1). 

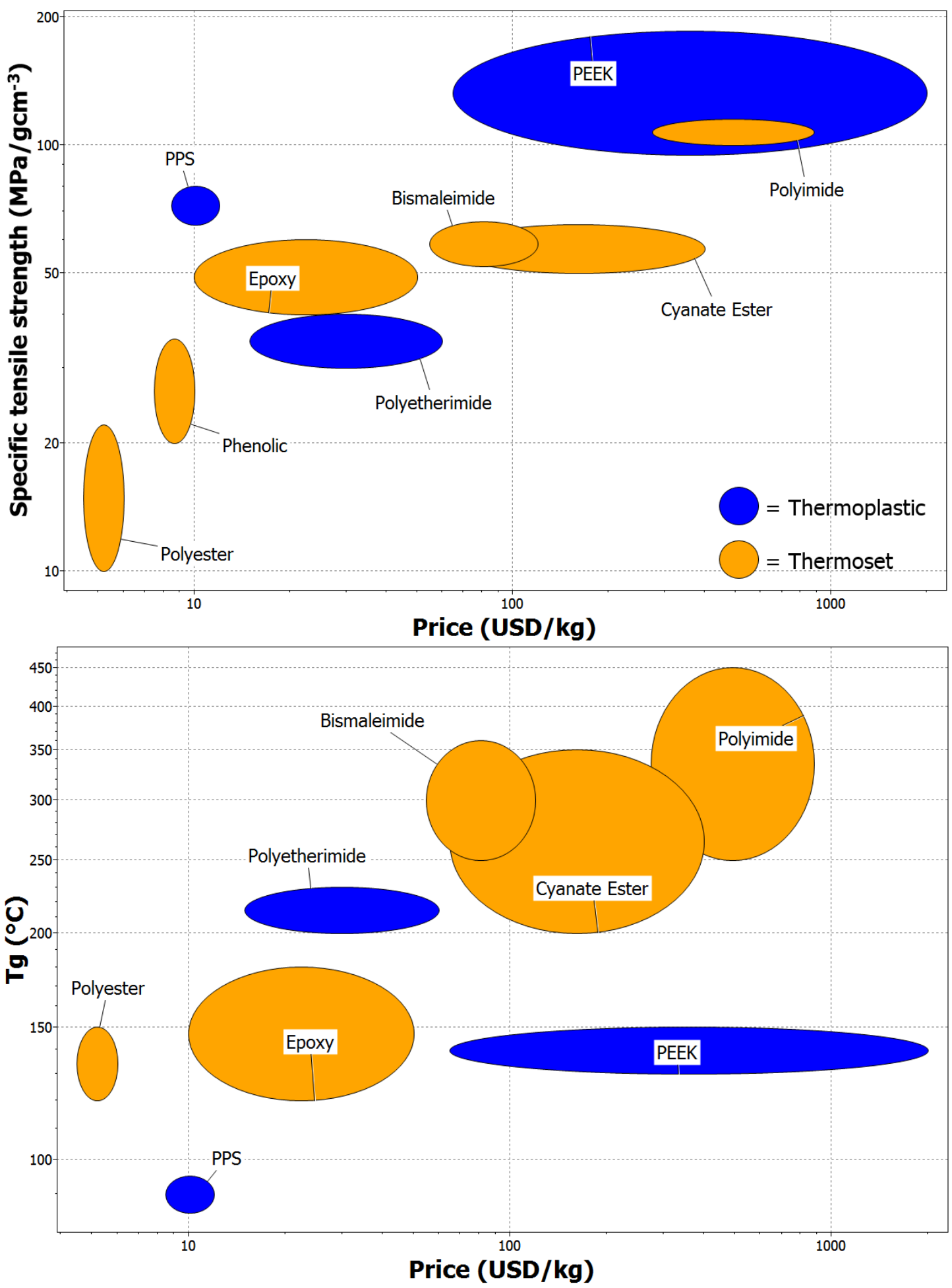

Figure 1. Comparative selected properties of higher performance polymers as a function of price. Key: PPS = poly(phenylene sulphide), PEEK = poly(ether ether ketone). 
Table 1. Representative structures of commercial thermoset monomers and selected representative physical and mechanical properties for their polymers (various sources)<smiles>Oc1cccc(CCc2cccc(O)c2Cc2ccccc2)c1</smiles>

(PF)

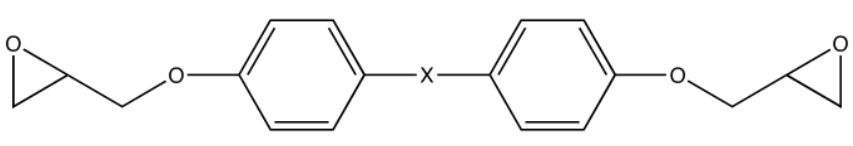

(ER)<smiles>[X]c1ccc(ON2C(=O)C=CC2=O)cc1</smiles>

(BMI)

(CE)

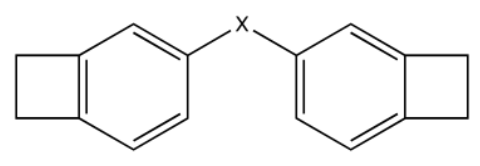

(BCB)

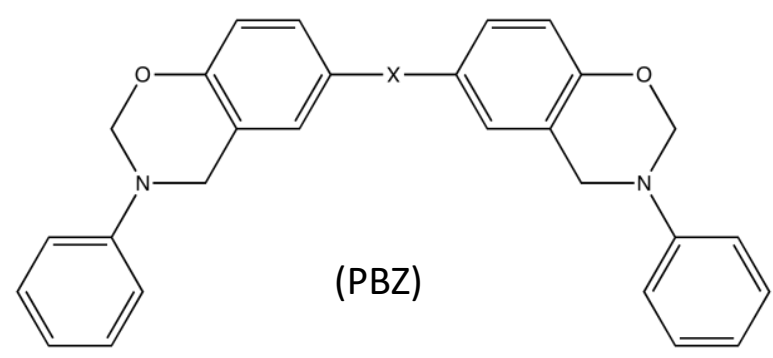

\begin{tabular}{|c|c|c|c|c|c|c|}
\hline Property & $\mathrm{PF}$ & ER & $\mathrm{BMI}$ & $\mathrm{CE}$ & $\mathrm{BCB}$ & PBZ \\
\hline $\begin{array}{l}\text { Cured density } \\
\left(\mathrm{g} / \mathrm{cm}^{3}\right)\end{array}$ & $\begin{array}{l}1.24- \\
1.32\end{array}$ & $1.2-1.25$ & $1.28-1.34$ & $1.1-1.35$ & 1.05 & $1.12-1.19$ \\
\hline TS (MPa) & $24-45$ & $59-90$ & $55-90$ & $56-120$ & $80-100$ & $44-64$ \\
\hline TM (MPa) & $3-5$ & $3.1-3.8$ & $3.6-4.8$ & $2.7-5.9$ & $2.7-3.1$ & $3.8-6.0$ \\
\hline Elongation (\%) & 0.3 & $3-4.3$ & $1.6-2.3$ & $2.5-3.8$ & 8 & $1.0-1.3$ \\
\hline $\mathrm{D}_{\mathrm{k}}(1 \mathrm{MHz})$ & $4-10$ & $3.8-4.5$ & 3.1 & $2.66-3.12$ & 2.65 & $2.4-3.5$ \\
\hline $\begin{array}{l}\text { Cure shrinkage } \\
(\%)\end{array}$ & 0.1 & $>3$ & $0.001-4$ & $<1$ & $<5$ & $0-2.9$ \\
\hline $\mathrm{T}_{5 \%}\left({ }^{\circ} \mathrm{C}\right)$ & $300-360$ & $260-340$ & $424-438$ & $280-410$ & 350 & $275-462$ \\
\hline $\mathrm{T}_{\mathrm{g}}\left({ }^{\circ} \mathrm{C}\right)$ & $90-290$ & $150-220$ & $265-320$ & $280-410$ & $>350$ & $180-350$ \\
\hline $\mathrm{CTE}\left(\mathrm{ppm} /{ }^{\circ} \mathrm{C}\right)$ & $\begin{array}{l}16.2- \\
24.7\end{array}$ & 59 & $45-50$ & $54-71$ & $40-50$ & $58-69$ \\
\hline
\end{tabular}

Key: $\mathrm{PF}=$ phenol-formaldehyde resins, $\mathrm{ER}=$ epoxy resins, $\mathrm{BMI}=$ bismaleimide resins, $\mathrm{CE}$ = cyanate ester resins; $\mathrm{BCB}=$ benzocyclobutene resins; $\mathrm{PBZ}=-$ polybenzoxazines (N.B. $\mathrm{X}$ may be e.g. aryl, alkyl, or a direct bond, and is commonly isopropyl), TS = tensile strength, $\mathrm{TM}=$ tensile modulus, $\mathrm{D}_{\mathrm{k}}=$ dielectric constant, $\mathrm{T}_{5 \%}=$ temperature at which $5 \%$ of mass is lost, $\mathrm{T}_{\mathrm{g}}=$ glass transition temperature (dry), CTE = coefficient of thermal expansion. 


\section{Results and Discussion}

The total number of research outputs recorded for all the selected polymers in the Web of Science ${ }^{\mathrm{TM}}$ over the period 1900-2018 are shown in Figure 2 (a). This serves to emphasise the dominance that the extended epoxy resin (ER) family holds over the performance resin market (with peak results some two orders of magnitude greater than the remaining performance resin systems), a point that will be addressed later in the essay. The inclusion of phenol-formaldehyde (PF) resins as a baseline provides a useful guideline since the profile is similar to the ER trace but once again an order of magnitude lower.

(a)

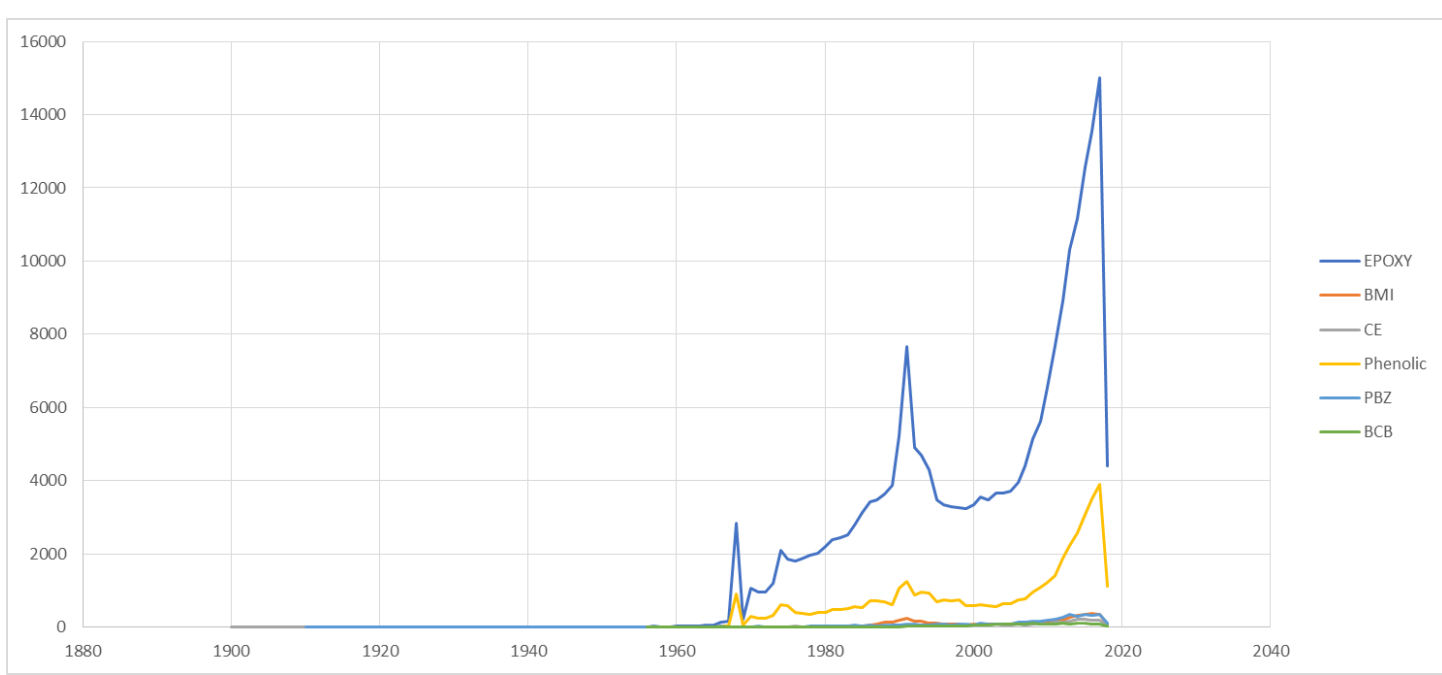

(b)

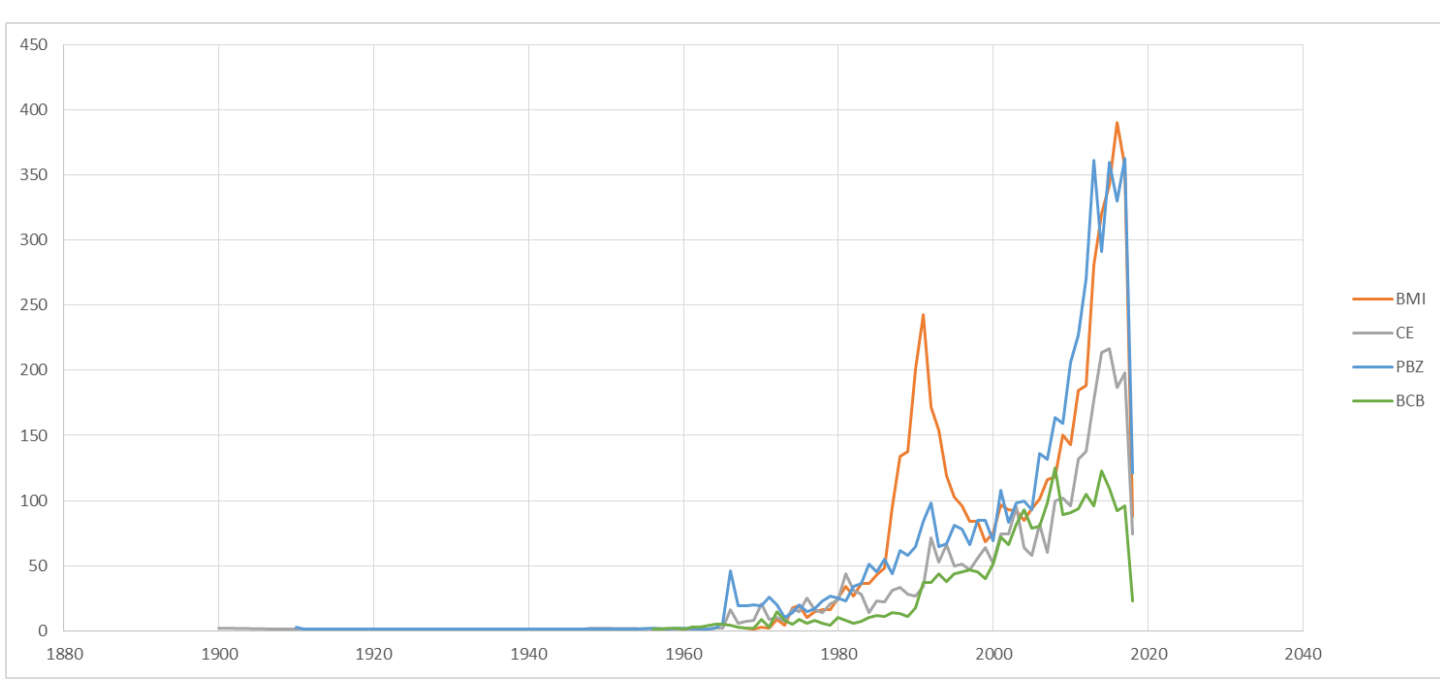

Figure 2. Research outputs for selected high performance polymers in which the individual polymers are named (a) complete data set including epoxy resins and phenol formaldehyde resins and (b) data with epoxy resins (ER) and phenol-formaldehyde (PF) resins omitted (data taken from the Web of Science ${ }^{\mathrm{TM}}$ for the period 1900- 2018).

\section{General Discussion}

Although an in-depth socio-economic and geo-political analysis is beyond the scope of this essay, the influence of key external factors must of course be taken into account to put the discussion into context. Although 
increasingly the derivation of some monomers from more sustainable sources, such as biomass, is being explored in new research, all of the materials described herein are derived from the by-products of petroleum processing. Thus, the price of oil (Figure 3) has had a significant influence on the cost of monomer production and a barometer of the health of the chemical industry. For instance, the first global oil crisis in 1973-74 was precipitated by the oil embargo imposed by the Organization of Arab Petroleum Exporting Countries (OPEC) in response to the Yom Kippur War in 1973 and led to a rise in the global price of oil from \$3 per barrel to nearly $\$ 12$ per barrel. This was followed by the 1979 oil crisis (the 'second oil shock'), which resulted from the reduction in oil output in the wake of the Iranian Revolution. Despite the modest reduction (ca. 4\%) in global production, panic buying of petrol was widespread, pushing the prices still higher; the price of crude oil reached $\$ 39.50$ per barrel over the course of a year.

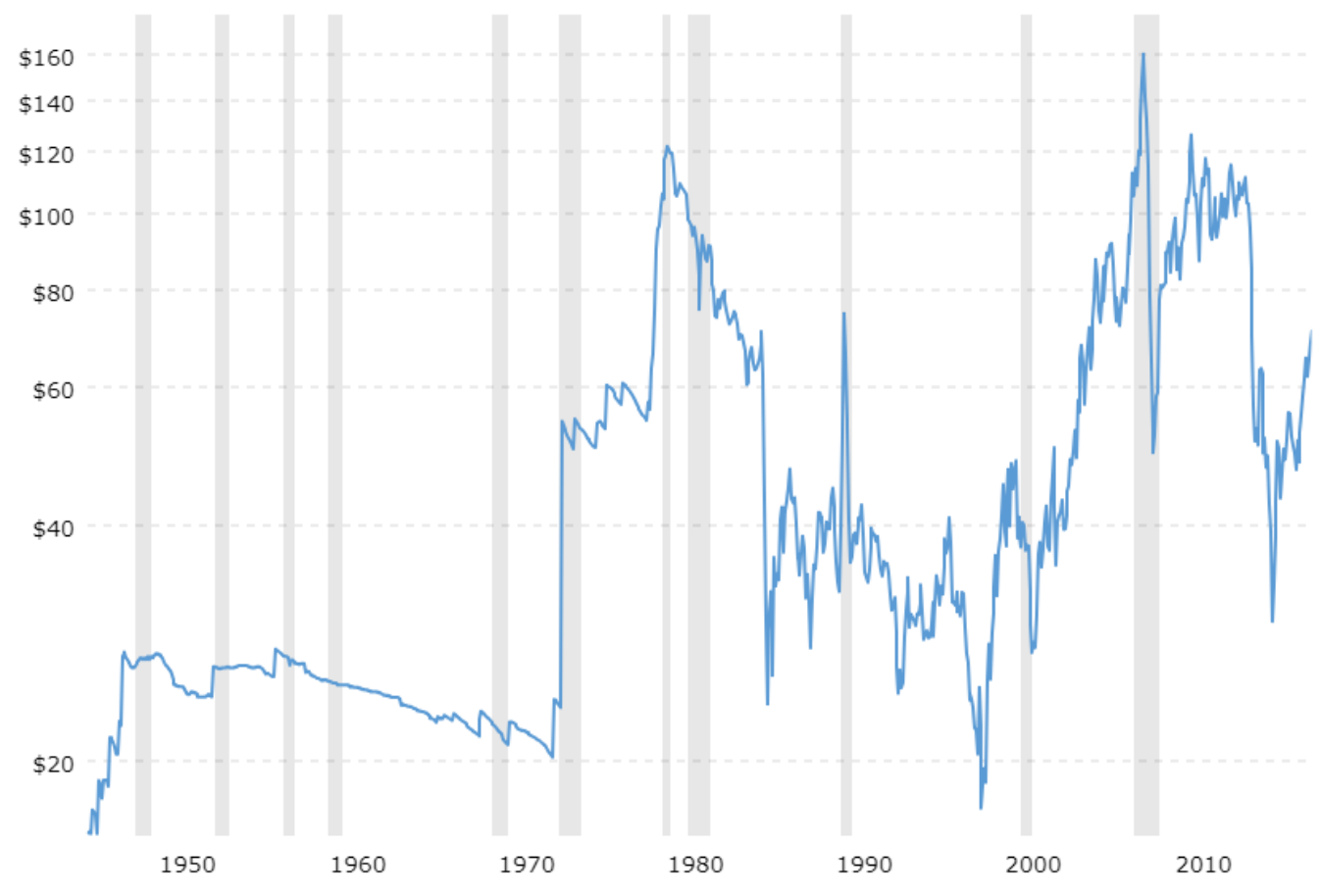

Figure 3. Price of West Texas Intermediate (WTI or NYMEX) crude oil prices per barrel ${ }^{10}$ back to $1946-2017$. The price of oil shown is adjusted for inflation using the headline CPI and is shown by default on a logarithmic scale. N.B. the shaded areas show the periods of economic recession.

Consequently, one might conjecture that the gradual fall in the global oil prices experienced from 1980-85 (and the emergence from recession), followed by the dramatic fall in 1985-86 may have fuelled the efforts to develop new materials (note the research outputs for all of the monomers selected show a significant upturn or spike at this point, 1990-1991). As a Chemistry placement student working as laboratory assistant for Exxon (in the Elastomers Division of Esso Chemical Ltd., in the Fawley oil refinery, near Southampton) in 1956-86, IH saw the catastrophic effects of a plunging oil price on a heavily dependent commercial business at first hand.

A second factor are the growth or decline in key markets (e.g. aerospace and microelectronics, and increasingly wind energy) that are satisfied by these materials. For instance, there was a marked increase in the numbers of orders placed with Airbus and Boeing for civil airliners ${ }^{11}$ over the period from 2003 to 2016 (Table 2), whose order books were fortunate to respond after the nadir following the banking crisis/credit 
crunch in 2008-2009. This trend mirrors the growth in outputs observed for ER from around 2009 onwards, Figure 2 (a).

Table 2. Orders placed with Airbus and Boeing for civil airliners over the period 2003-2016

\begin{tabular}{lll}
\hline Year & Airbus & Boeing \\
\hline 2003 & 284 & 248 \\
2004 & 372 & 272 \\
2005 & 1111 & 1010 \\
2006 & 824 & 1007 \\
2007 & 1458 & 1279 \\
2008 & 900 & 600 \\
2009 & 310 & 263 \\
2010 & 644 & 625 \\
2011 & 1608 & 921 \\
2012 & 914 & 1339 \\
2013 & 1619 & 1531 \\
2014 & 1796 & 1550 \\
2015 & 1190 & 878 \\
2016 & 949 & 848 \\
\hline Data & & from \\
(https://www.statista.com/statistics/264492/aircraft-orders-from-airbus-and- \\
boeing/)
\end{tabular}

This was a pivotal period for the aerospace sector as the production of the Airbus A380, and to an even greater extent the Airbus A350 XWB and the Boeing A787 Dreamliner, heralded the use of much larger quantities of advanced composites in the construction of the airframe (Figure 4). The fuselage of the Boeing 787 is based on a third generation, toughened epoxy resin (comprising the diglycidyl ether of bisphenol $\mathrm{F}$ and triglycidyl aminophenol), while TORAYCA $®$ T800/3900-2 is used in the Boeing 777 tail fin. Consequently, the aerospace sector impacts directly on the demand for epoxy resins as the mainstay of advanced composite production in civil aerospace as these materials account for at some $90 \%$ of these matrices. 


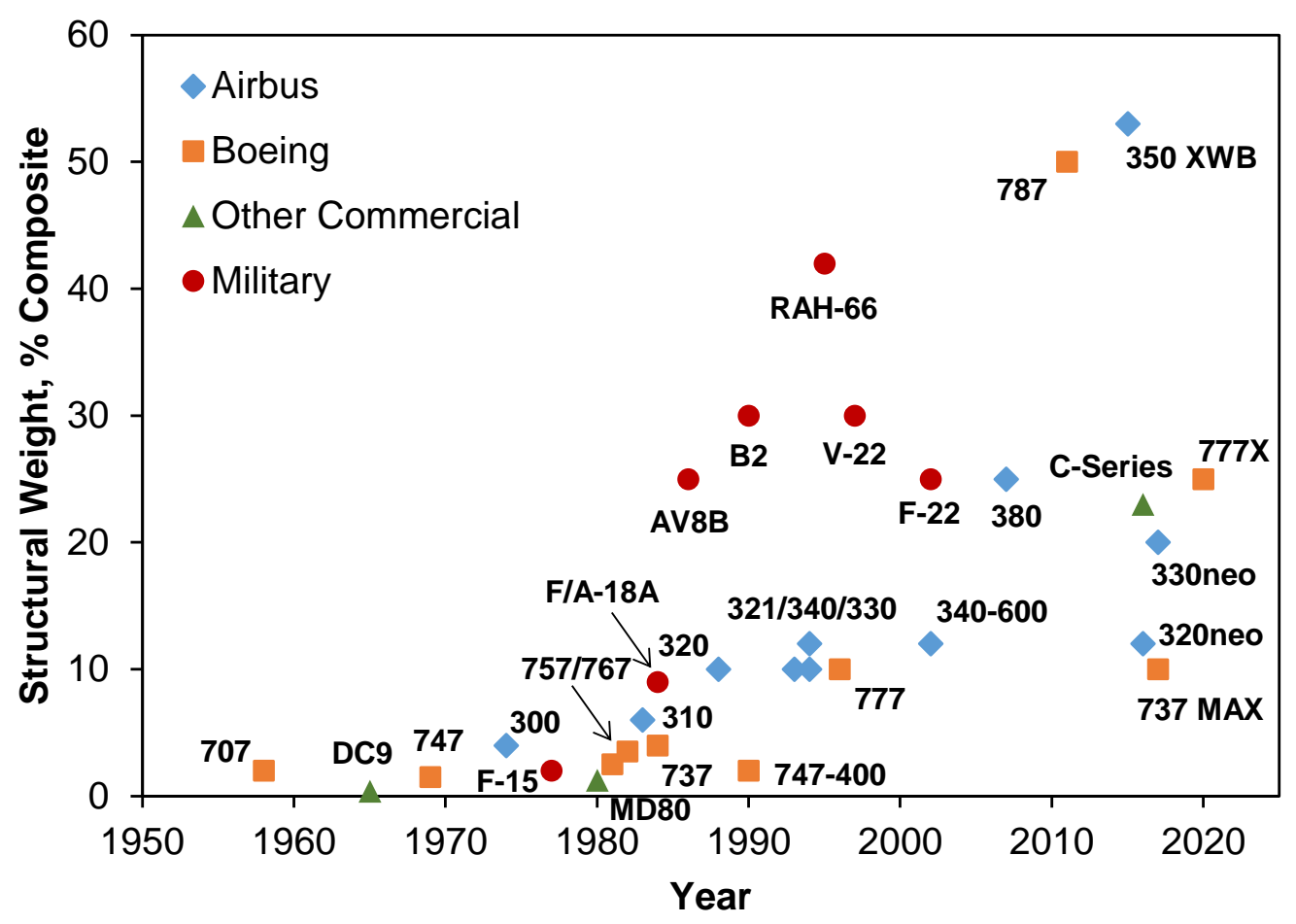

Figure 4. Comparative use of advanced composites (by weight) in representative civil and military aircraft from 1950 to the present.

A similar argument might be made for the growth in the demand for multichip modules and integrated circuit packaging, driven by the sales of smart phones and other consumer electronics. For example, in 2009 the sales of personal desktop computers were under 300 million units (compared with around 150 million smart phones), but in the intervening seven years the demand for smart phones had far outstripped the older technology. So that by 2016, while just over 200 million PCs were sold in that year, some 1.45 billion smart phones were shipped ${ }^{12}$. Although the quantities of the resins used per unit is on a somewhat smaller scale than in aerospace, the commercial impact was particularly felt by BMI and CE resin producers (for when combined as bismaleimide-triazine (BT) resins, they form a dielectric polymer which is a major component in this application).

\section{Bismaleimide Resins}

The concept of the present publication arose during while conducting research for two reviews of the most recent developments in bismaleimide (BMI) chemistry ${ }^{13}$ and their application to advanced composites ${ }^{14}$. One of the authors $(\mathrm{IH})$ carried out novel BMI (and then $\mathrm{CE}$ ) research at the very start of his research career in 1987, and a satisfying symmetry emerges as the co-author RI is now carrying out BMI research in BMI and CE resins at the start of his research career. Back in the late 1980s, when these resin systems were being touted as the 'next big thing', set fair to take the world of advanced composites by storm. Interest in synthetic BMI chemistry was high, with numerous research publications published during the latter part of the 1980s and culminating in several comprehensive reviews by Dr Horst Stenzenberger, the acknowledged expert in this area ${ }^{15-17}$. Numerous data tables, containing some twenty or more BMI monomers, all prepared using clean and comparatively high yielding preparative procedures ${ }^{18}$ - the future looked very bright indeed for BMI resins. The peak year of 1991 saw almost 250 outputs, but this was followed by a comparative slump so that a 
decade later the number had fallen to around one third that number. So what went wrong? Why did all that promise evaporate, and was this issue unique to BMIs?

Of course, these are somewhat provocative questions and deliberately so, but the answer to the last question is an emphatic negative. This apparent paucity of research activity began to pick up once again in 2001 and has increased more dramatically more recently with almost 400 research outputs published in 2017. Nevertheless, now in 2018, research articles with a focus on the synthesis of entirely new BMI monomers are rare and the introduction of new commercial building blocks (as opposed to formulations) is quite an unusual event $^{19}$. A comparatively small number of commercial products are available, but they are based on perhaps half a dozen commercial monomers (available singly or as blends).

One of the principal barriers to the more widespread adoption of BMIs is perhaps the customer's perception of their toxicity, resulting from the use of aromatic diamine precursors, principally methylene dianiline (MDA). In Kerimid 601, one of the earliest commercial BMIs ${ }^{20}$, the existence of free MDA residues in the product were around $6-12 \%$ and thus a significant concern during the 1980 s since MDA is considered a potential occupational carcinogen by the US National Institute for Occupational Safety and Health and classified by the ECHA as a 'substance of very high concern' (SVHC) and placed on the authorisation list. The Occupational Safety and Health Administration has set a permissible exposure limit at 0.01 ppm over an eighthour time-weighted average, and a short-term exposure limit ${ }^{21}$ at $0.10 \mathrm{ppm}$, making it increasingly difficult to market MDA-based commercial products. Nevertheless, the basic approach has stood the test of time and Compimide 200 is based on the same chemistry and structures ${ }^{22}$, but is significantly more refined with a dramatically reduced MDA content $(<0.1 \%)$. The customer's perception of a high MDA content is now being corrected as seen by the increased application of BMIs, although other barriers that are yet to be completely addressed are the more complicated processing cycles (higher temperature, longer timescales) and higher unit cost compared with epoxies (Figure 1).

\section{Cyanate Ester Resins}

Cyanate esters suffered a similar problem to BMIs when initially introduced, being prepared from a cyanogen halide (to the uninitiated a 'cyanide' regardless of the presence of covalent rather than ionic bonding) and having a name that was uncomfortably and unavoidably mispronounced as a 'cyanide ester' by end users on more than occasion in the author's earshot. This misunderstanding, associated with the perception of monomer toxicity undermined user confidence in the material, despite a very low monomer toxicity (LD50 $\geq 3$ $\mathrm{g} / \mathrm{kg}$ compared with $\mathrm{NaCl}, 4 \mathrm{~g} / \mathrm{kg})^{23}$ and low concentration of hydrogen cyanide $(3 \mathrm{ppm}$ ) in the combustion products $^{24}$.

During the late 1970s, the poor steam resistance of one of the first commercial products (Triazine A from Mobay) was a significant problem leading to outgassing and explosive delamination of laminates in the incompletely cured resin. The phenomenon was subsequently tracked down to the low purity of the monomer, promoting the slow conversion to carbamate species and rapid decarboxylation at elevated postcure temperatures (above $200^{\circ} \mathrm{C}$ ). This shortcoming was remedied during the 1990 s through the release of high purity (99+\%) monomers by Interez/HiTek and was combined with concerted efforts by Dave Shimp to publicise these materials through peer reviewed and conference publications, and the subsequent release of a book detailing the science and technology ${ }^{12}$. Nevertheless, the issues with poor processability knocked consumer confidence and the dip in outputs as a result is clearly apparent, Figure 1 (b).

The interest in cyanates waxed and waned during this period, with a reduction in the number of available commercial monomers from 9 in 1994, to 3 or 4 in 2018 (with the commercial offerings now based principally on the following precursors: bisphenol A, bisphenol $E$, and novolak) coupled with disenchantment arising from 
processing characteristics that were more demanding and less forgiving than typical epoxy resins. However, there has been a significant growth in the use of cyanates during the $21^{\text {st }}$ century, with resurgence in interest during the last decade (e.g. in 2014-15 over two hundred outputs were recorded). This upsurge in interest has largely been driven by the availability of cyanated novolaks (cyanate oligomers) with high thermal stability (approaching that of phenolics) and the exceptionally low dielectric constant (and low loss properties) developed in the cured polymers (Table 1), still unbeatable in commercial competitor resins. This has ensured the cyanates have carved a niche for themselves in technological fields (e.g. radomes and microwave technology) where there are no direct competitors.

\section{Bisbenzocyclobutene Resins}

There was a marked increase in the degree of interest expressed in benzocyclobutene (BCB) resins during the 1990s, many patents (15-35/year) were generated and a multitude of conference papers were presented, outlining their potential benefits as chemically versatile, reactive monomers. The principal reason for the interest in the materials was governed by the claims for the reactivity in processing and thermal performance of the cured polymers. There was a loss of confidence when the high thermal stability observed in dynamic TGA experiments was not matched to the same degree in extended isothermal studies. Whilst this dealt a debilitating blow to the wider commercialization and adoption of the materials in high temperature aerospace applications, the commercial effort was re-focused towards the microelectronics field. Thus, the Cyclotene 4000 series was offered by Dow ${ }^{25}$ in 1994 and the growth in research outputs involving BCB resins continues to grow steadily, albeit at a fixed rate; they are still primarily offered in the form of photopolymerisable products for microelectronic technology, where BMIs retain a larger market share.

\section{Phenol-Formaldehyde Resins}

Phenol-formaldehyde (PF) resins (phenolics) were included as 'baseline' comparison. These share some properties (high thermal stability, high char yield and high $T_{g}$ ) in common with higher performance systems (Table 1), despite remaining a lower cost alternative (Figure 1). Applying, retrospectively, the criteria for a successful synthesis to the polymer ${ }^{26}$, the key parameters influencing the long-term success of phenolics are the relatively cheap precursors (phenol and formaldehyde), which are both readily available as byproducts of other commercial processes. The process involves comparatively few preparative steps, which are relatively high yielding, so atom efficiency is good. Although not entirely benign (formaldehyde LD $_{50}$, median dose, of $100 \mathrm{mg} / \mathrm{kg}$, oral rat ${ }^{27}$; phenol; phenol $\mathrm{LD}_{50}, 317 \mathrm{mg} / \mathrm{kg}$, oral rat ${ }^{28}$, the compounds are amenable to handling on large scales. Phenolics are quite versatile and able to occupy a number of market niches, including composites, adhesives (which form the largest single market in the $21^{\text {st }}$ century), and coatings. The timing of the development should not be overlooked since these were the first family of wholly synthetic thermosetting polymers to be commercialised by Leo Baekeland ${ }^{29}$ and at that time no synthetic competitor resins were in existence. The timing was also fortuitous as the availability of Bakelite ('the material of a thousand uses') ${ }^{30}$ coincided with the rapidly growing interest in new materials during the 1920s following the privations of society as a result of wartime austerity ${ }^{31}$.

\section{Epoxy Resins}

Epoxies (ER) buck the general trend insofar as they display rapid increase in research outputs during the 1960s and this growth has been maintained over period of some 50 years, with interest simply soaring from the early 2000s. Furthermore, there has been a proliferation in the number of commercial monomers (i.e. the number of commercial monomers that were available in 1990 is similar to 2018, is based on some 15 families, unlike 
both BMIs and cyanate esters). Note, that the magnitude of effort too, so that for 2014 nearly 2400 patents were identified, at least an order of magnitude greater than the most prolific of the competitors presented here.

So, what makes the epoxy the 'go to' resin system for most industries? Why have they succeeded where others have failed? In common with BMIs, epoxy monomers are normally produced from toxic precursors (an aromatic diamine in the case of tetraglycidyldiaminodiphenyl methane, TGDDM, and epichlorohydrin in the glycidyl ethers). There is no tangible reason why the chemistry should be markedly cheaper than e.g. BMls (involving a diamine, an anhydride, and a dehydrating agent). However, there are key differences: at the time of the initial reports and patents ${ }^{32}$, there were no real competitors available to offer a similar balance of properties, so there was freedom to develop the field and for their adoption in many areas. Of course wider adoption ultimately means that economies of scale begin to kick in so thus reducing the price and increasing the attractiveness of the matrix. Consequently, epoxy resins now represent a mature and successful technology, despite (or perhaps because) the fact that they are not specialised, niche products, offering moderate rather than especially high performance.

\section{Benzoxazine Resins}

The inclusion of benzoxazine resins (PBZ), at a comparatively early stage of their commercial life, provides a useful comparison as they offer many of the key properties exemplified by the other competitors (Table 1) with the promise of cheaper monomers and superior processing to P-F resins. Note that the level of commercial activity reviewed dates from the first report of difunctional monomers in 1994 by Ning and Ishida $^{33}$. Up until 2011, the growth in the research outputs had been practically exponential ${ }^{34}$ and this is clear from the data, Figure 1 (b). The rise in the number of patents has been equally dramatic, with some 40 published in 1994 (many relating to low molecular weight molecules for pharmaceuticals), but over 400 in 2015. Now, PBZs are entering a key stage in their development, with strong growth and interest, and the crucial question is whether the family follows an ER, a BMI, or CE pathway in its future development. Is the key to success to compete with P-F and ER resins on cost, but to emphasise higher performance, or to offer similar properties to BMIs with the promise of lower cost?

\section{Conclusions}

High performance polymers are widely used in the composites industry, and particularly the aerospace industry. Thus, the users are understandably inherently conservative and governed by demanding legislation and long, costly timescales for materials qualification. Consequently, an early problem/issue can spell disaster for any new resin system. Lack of user confidence (or user acceptance) can stop a product in its tracks, even when it might have significant potential. The oft-heard comment from end users that, 'we tried that resin system and it didn't work' may not relate to an optimized system.

Competition is key: materials that are released in a virgin market have room to develop and grow, facilitating wider adoption.

If a polymer has properties that are hard to replicate with another resin then it may obtain a second (or even rarely a third) opportunity to prove itself and achieve commercial adoption.

To return to Darwin, "One general law, leading to the advancement of all organic beings, namely, multiply, vary, let the strongest live and the weakest die." ${ }^{35}$. 


\section{Experimental Section}

Methodology. The methodology used in this essay attempts to achieve the difficult aim of quantifying the interest (in both academic research and commercial development) by monitoring the number of research outputs and commercial monomers and during the lifetime of the polymer. Such an undertaking is prone to misinterpretation, since the advent of the internet and web-based searches has undoubtedly affected profoundly the way in which research data are disseminated; nevertheless it forms a useful starting point. For each polymer family, the number of research outputs: peer reviewed and published conference proceedings and international patents were recorded over the lifetime of the polymer from the first report ${ }^{9}$ (using the Web of Science ${ }^{\mathrm{TM}}$ ). Similarly, the lifetime of individual commercial products is difficult to determine precisely, but an attempt has been made to include the breadth of individual commercially available monomers as well.

\section{Acknowledgements}

The authors thank Dr Carwyn Ward, Bristol Composites Institute, for valuable discussions during the production of this manuscript). Rl's research was supported by the Engineering and Physical Sciences Research Council through the EPSRC Centre for Doctoral Training in Advanced Composites for Innovation and Science [grant number EP/L016028/1].

\section{References}

1. On the Origin of Species By Means of Natural Selection or The Preservation of Favoured Races in the Struggle for Life, Darwin, C., John Murray: London, 1859, p 126.

2. High Performance Thermosets. Chemistry, Properties, Applications, Lin, S.-C.; Pearce, E.M. Hanser: Munich, 1993, pp 1-11.

3. Chemistry and Technology of Epoxy Resins, Ellis, B., Ed., Blackie Academic \& Professional: Glasgow, 1993.

4. Stenzenberger, H.D. Addition polyimides, in Polyimides, Wilson, D.; Stenzenberger, H.D.; Hergenrother, P.M. Eds. Blackie: Glasgow, 1990, pp 79-128.

https://doi.org/10.1007/978-94-010-9661-4 4

5. Chemistry and Technology of Cyanate Ester Resins Hamerton, I. Ed. Blackie Academic \& Professional: Glasgow, 1994.

6. Phenolic Resins: Chemistry, Applications and Performance Future Directions, Knop, A.; Pilato, L.A.

7. Springer-Verlag: Berlin, 1985.

8. Kirchhoff, R.A.; Bruza, K.J. Polymers from benzocyclobutenes, Adv. Polym. Sci., Volume 117: High performance polymers, Hergenrother, P.M., Ed., Springer-Verlag: Berlin, 1994, pp 1-66.

https://doi.org/10.1007/BFb0021196

9. Handbook of Benzoxazine Resins Ishida, H.; Agag, T., Eds., Elsevier: Amsterdam, 2011.

10. Web of ScienceTM, Thompson Reuters Corporation and Clarviate Analytics.

http://www.macrotrends.net/1369/crude-oil-price-history-chart (accessed 16 May 2018).

11. D. Loesche, Airbus vs. Boeing. A Head to Head Transatlantic Rivalry, https://www.statista.com/chart/11416/number-of-aircraft-ordered-by-customers-and-delivered-byairbus-and-boeing/(accessed 16 May 2018). 
12. Carton, B.; Mongardini, J.; Li, Y. Smartphones Drive New Global Tech Cycle, but Is Demand Peaking? https://blogs.imf.org/2018/02/08/smartphones-drive-new-global-tech-cycle-but-is-demand-peaking/IMF Blog (accessed 16 May 2018).

13. Iredale, R., Ward, C., Hamerton, I. Modern advances in bismaleimide resin technology: a 21st century perspective on addition polyimides, Prog. Polym. Sci. 2017; 69: 1-21.

https://doi.org/10.1016/i.progpolymsci.2016.12.002

14. Iredale, R., Hamerton, I., Ward, C. Modern developments in BMI composite technology, 2021, in preparation.

15. Stenzenberger H. Recent advances in thermosetting polyimides. Brit. Polym. J. 1988; 20: 383-96. https://doi.org/10.1002/pi.4980200503

16. Stenzenberger H. Bismaleimide Resins. In: Miracle, D.B.; Donaldson, S.L. Eds. ASM Handbook, Vol. 21 Composites, 2001, pp 97-104.

https://doi.org/10.31399/asm.hb.v21.a0003364

17. Stenzenberger, H.D. Addition polyimides, Adv. Polym. Sci., volume 117: High performance polymers, Hergenrother, P.M., Ed., Springer-Verlag: Berlin, 1994, pp. 165-220.

https://doi.org/10.1007/BFb0021199

18. Searle N.E. Synthesis of N-Aryl-Maleimides. US Patent 2444536, 1948.

19. Dersham, S.M. ; Mizori, F.G. ; Huneke, J.T. Materials and Methods for Stress Reduction in Semiconductor Wafer Passivation Layers. US Patent 8710682, 2014.

20. Bargain, M.; Combet, A.; Grosjean, P. Cross-linked Resins. US Patent 3562223, 1971.

21. NIOSH Pocket Guide to Chemical Hazards. Department of Health and Human Services;,2007.

22. Compimide 200 Formulated Bismaleimide Resin, Technical Information, Evonik Nutrition and Care GmbH, January 2016.

www.evonik.com

23. Shimp, D.A. Technologically driven applications for cyanate ester resins, In Reference 5, p 283.

24. Lyon, R.E.; Walters, R.; Gandhi, S. Combustibility of cyanate ester resins, DOT/FAA/AR-02/44, Office of Aviation Research, Washington DC 20591, June 2002, p 14.

25. So, Y.-H.; Garrou, P.; Im, J.-H.; Scheck, D.M. Benzocyclobutene-based polymers for microelectronics. Chemical Innovation, 2001, 31, pp 40-47.

26. Norman, R.O.C.; Coxon, J.M. Principles of Organic Synthesis, 3rd Ed. CRC Press: Cheltenham, 1993. https://doi.org/10.1007/978-94-011-2166-8

27. http://chemchem.sis.nim.nih.gov/chemidplus/rm/50-00-0 (accessed 11 May 2016).

28. Crystallised Phenol, Material Safety Data Sheet No. 18380, Fisher Scientific, Created 15 July, 1999 (revised 20 July, 2009).

29. Baekeland, L.H., Method of making insoluble products of phenol and formaldehyde, US Patent 942,699, 1909.

30. Reboul, P., Britain and the Bakelite Revolution, In: The Development of Plastics, S.T.I. Mossman and P,J.T. Morris, Eds., Royal Society of Chemistry: Cambridge, 1994, pp 26-37.

31. Meikle, J.L., Materia Nova: Plastics and Design in the U.S., 1925-1935, In: The Development of Plastics, Mossman, S.T.I.; Morris, P.J.T., Eds., Royal Society of Chemistry: Cambridge, 1994, pp 38-53.

32. Schlack, U.S. Patent 2,131,120 (1938); Schlack, German Patent 676,117 (1939); Castan, P. U.S. Patent 2,324,483 (1943); Castan, P. Swiss Patent 211,114 (1940).

33. Ning, X., Ishida, H. J. Polym. Sci. A, Polym. Chem. 32, 1994, 1121-1129. 
34. Reference 8, p. xix.

35. Reference 1, p. 244.

This paper is an open access article distributed under the terms of the Creative Commons Attribution (CC BY) license (http://creativecommons.org/licenses/by/4.0/) 